
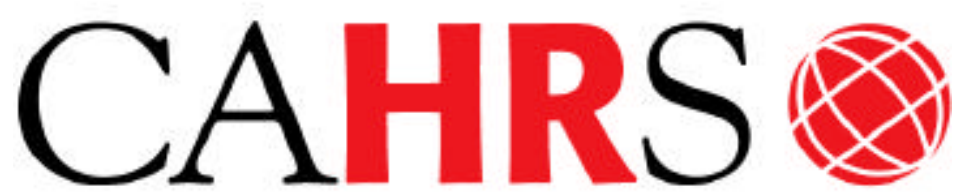

Center for Advanced Human Resource Studies
CAHRS / Cornell University 187 Ives Hall

Ithaca, NY 14853-3901 USA

Tel. 607 255-9358

www.ilr.cornell.edu/depts/CAHRS/

\title{
VARINGPAPER SPIES
}

\section{Crafting A Human Resource Strategy To Foster Organizational Agility: A Case Study}

Richard A. Shafer

Lee Dyer

Janine Kilty

Jeffrey Amos

G. A. (Jeff) Ericksen

Working Paper 00 - 08 


\title{
Crafting A Human Resource Strategy To Foster Organizational Agility: A Case Study
}

\author{
Richard A. Shafer \\ Lee Dyer \\ Janine Kilty \\ Jeffrey Amos \\ G. A. (Jeff) Ericksen
}

Support for this study was provided by the Center for Advanced Human Resource Studies, ILR School, Cornell University and by the Agility Forum, Lehigh University

http://www.ilr.cornell.edu/cahrs

This paper has not undergone formal review or approval of the faculty of the ILR School. It is intended to make results of Center research available to others interested in preliminary form to encourage discussion and suggestions. 


\section{ABSTRACT}

A decade ago, the CEO of Albert Einstein Healthcare Network (AEHN), anticipating a tumultuous and largely unpredictable period in its industry, undertook to convert this organization from one that was basically stable and complacent to one that was agile, "nimble, and change-hardy". This case study briefly addresses AEHN's approaches to business strategy and organization design, but focuses primarily on the human resource strategy that emerged over time to foster the successful attainment of organizational agility. Although exploratory, the study suggests a number of lessons for those who are, or will be, studying or trying to create and sustain this promising new organizational paradigm. 


\section{INTRODUCTION}

Increasingly, organizations find themselves operating in environments characterized by unprecedented, unrelenting, and largely unpredictable change. So it's not surprising to find that serious searches are underway for new and better ways of strategizing, organizing, and operating - that is, managing - in dynamic and turbulent circumstances. The proscriptions and prescriptions are many and varied, and most have profound implications for the management of people. Even so, very few have provided in-depth analyses of people-related issues and, to date, we know very little about what it takes to develop and implement human resource strategies appropriate to high change, or agile, organizations (Dyer \& Shafer, 1999).

This, then, is a case study of a healthcare organization that a decade ago deliberately set out to become an agile - or what the CEO at the time referred to as a "nimble, changehardy" - organization. The idea was to create an organization that would be capable of thriving in the rock and roll realities of the healthcare industry during the 1990s without experiencing constant internal change and turmoil. The focus here is on the specifics of the human resource strategy that emerged in this organization and the ways in which this strategy contributed to achieving a truly agile organization. While some attention is given to the organization's transformation from a staid, limited service operation to a dynamic, integrated healthcare network, this is primarily for context. The emphasis is on the end-state attained -- that is, on the human resource strategy -- and not, as is more commonly the case, on the change process per se.

The explication begins with a brief description of the methodology used to conduct the study and, subsequently, of the organization studied and its unique approach to business strategy. Thereafter, attention is turned to an overview, and then to the specifics, of the organization's agility-driven human resource strategy. The presentation unfolds, as we believe the formation of human resource strategy should, from the organization's business strategy back through requisite employee behaviors and attributes to key human resource initiatives and eventually to specific human resource programs and practices (Boudreau \& Ramstad, 1999; Ulrich, 1997). At the end, we provide a summary of the study's major findings and the corresponding implications for future research and practice. Because the territory is new and the study is exploratory, the findings are presented as tentative propositions rather than firm conclusions. Our hope is that these will prove useful in future efforts to better understand and develop human resource strategies appropriate for agile organizations, a form that many believe will constitute the dominant organizational paradigm of the $21^{\text {st }}$ century (Dyer \& Shafer, 1999; 
Fradette \& Michaud, 1998; Goldman, Nagel \& Price, 1995; Gunneson, 1997; Youngblood, 1997).

\section{THE METHODOLOGY}

Following Yin's (1994) guidance for embedded case study design, the research began with the development of a preliminary model based on information obtained from reviews of the (rather sparse) literature on organizational agility and related concepts and from informal interviews and discussions with thought leaders and consultants familiar with the concept. The preliminary model, in turn, was used to generate an initial set of research questions that served to guide, but not constrain, data collection at the chosen research site. Consistent with the tenets of developing "grounded theory" (Glaser \& Strauss, 1967), the model, as well as the data collection techniques and procedures, were amplified and revised on an ongoing basis as new information was obtained, coded, and analyzed. This process continued until data convergence suggested that the emerging depiction of the organization's human resource strategy was complete and accurate. (For a more thorough description of the study's methodology, see Shafer, 1997.)

Case selection was based on four theoretically relevant criteria (Eisenhardt, 1995). First, the organization had been and was operating in a dynamic, rapidly changing, highly competitive environment. Second, as noted, it was pursuing a business strategy based on agility or nimbleness. Third, human resource strategy was central to this pursuit. And fourth, there was preliminary evidence to suggest that the chosen business and human resource strategies were producing positive organizational results.

Data were collected from several sources by multiple investigators over a two-year period (1995 to 1997). Three of the authors conducted a total of 30 semi-structured interviews with 19 informants representing various organizational levels and functions, along with numerous informal discussions (hallway and lunchroom conversations and the like) throughout the organization. A typical formal interview lasted one hour, although some continued for as long as three hours; a few key informants were interviewed more than once. In addition, one of the authors (Shafer) conducted first-hand observations of several events (e.g., meetings and training sessions) at the organization throughout the course of the study. Further, all authors participated in analyses of archival materials such as memos, policy statements, procedural manuals, newsletters, and forms. Finally, one of the authors (Kilty) provided the perspective of a participant observer, since she served as the organization's Vice President of Human Resources from 1989 to 1998. 
Data analysis, as noted, focused on the content of the human resource strategy that eventually emerged in the organization. Basically, the strategy was reconstructed piece by piece by identifying patterns in streams of decisions and actions (Mintzberg, 1989) in an effort to capture actual events (rather than simply good intentions or unrealized plans). Emerging findings were compared with the evolving human resource strategy literature on an ongoing basis (Eisenhardt, 1995). The result is an inductively derived model of the organization's agilitydriven human resource strategy that closely fits the case data (Glaser \& Strauss, 1967), but nonetheless is a stylized representation of reality that is obviously and appropriately devoid of much of the "noise" experienced by those who were directly involved (Eisenhardt, 1995).

\section{THE ORGANIZATION AND THE CHALLENGE}

The organization was founded in 1865 as the Jewish Hospital of Philadelphia. It was created to provide a culturally sensitive environment for Jewish patients and a place where Jewish doctors of the time could practice. A private, not-for-profit organization, for a long time it was known as Einstein Medical Center and consisted primarily of an acute care hospital. But, more recently, having become the Albert Einstein Healthcare Network (AEHN), it had begun to reach out to a broader constituency and into a host of related medical services provided primarily through outpatient centers and rehabilitative and psychiatric care facilities.

\section{Anticipating the Nineties}

In 1990, AEHN's newly appointed CEO led a "trends study" designed to explore the major developments that would be affecting the healthcare industry during the coming decade. The basic conclusion: While the industry was almost certainly in for a period of severe turbulence, it was virtually impossible to predict with any degree of precision or confidence either the most likely events or their probable implications.

These findings were unsettling, since the CEO was most eager to set AEHN on a path of rapid growth based on a broad vision consisting of two major components. First, he aimed to transform AEHN into a truly comprehensive healthcare network providing a full range of highquality services (from obstetrics to long-term and home care, from preventive thru sub-acute to acute care, and so on) to clientele in nearby neighborhoods. Second, he proposed to create a small number of magnet services in Philadelphia that would provide world-class specialized care (such as behavioral health, cardiac care, and transplantation services) to clientele who would be attracted on a regional or even national basis. Given the high degree of uncertainty facing the industry, however, the CEO came to realize that his vision would take a long time to realize and would have to be pursued intermittently through a series of opportunistic moves 
rather than in a highly planned way (i.e., the strategies pursued would be more emergent than deliberate [Brown \& Eisenhardt, 1998; Mintzberg, 1989]).

Clearly, as we now know, the CEO's "trends study" was prophetic. Throughout the 1990s, AEHN, not unlike other healthcare providers, was buffeted by an ongoing series of shocks administered by outside forces over which it had little or no control (see Figure 1). To cite just a few:

Constant and significant changes and cutbacks in Medicare and Medicaid put pressure on both procedures and costs. This was especially acute for AEHN since it served sizable older and indigent populations and, in the early ' 90 s, derived about $75 \%$ of its revenue from these two public programs.

$>\quad$ Managed care organizations (HMOs and PPOs) made major inroads in the Philadelphia area. This created intense competition to win potentially lucrative contracts by providing an increasingly wide range of services at ever-lower costs (necessitating endless efforts to rationalize internal operations).

Local competition intensified and periodically imploded. Pressure on reimbursements led to shorter hospital stays which, over time, created an estimated $50 \%$ surplus of beds in the greater Philadelphia area. Predictability, this resulted in a flurry of mergers, acquisitions, and joint ventures and, in turn, cutthroat competition among the survivors to attract patients. For two or three years during the mid-nineties, for example, there was an intense scramble to buy up or affiliate with the practices of local physicians who typically were the gatekeepers who decided where patients would be directed for specialized treatment and hospitalization.

There were countless major advances in science and technology. AEHN was under (somewhat self-induced) pressure to employ these new developments to provide state-of-the art care. But, they were difficult to keep up with, costly to acquire, and often very challenging to implement. 
FIGURE 1

A Vision of Rapid Growth and Organizational Transformation in a Turbulent Healthcare Environment

Constant and Significant

Changes and Cuts in Medicare and Medicaid

Managed Care (HMOs, PPOs)

\section{Transformation in a Turbulent Healthcare Environment}

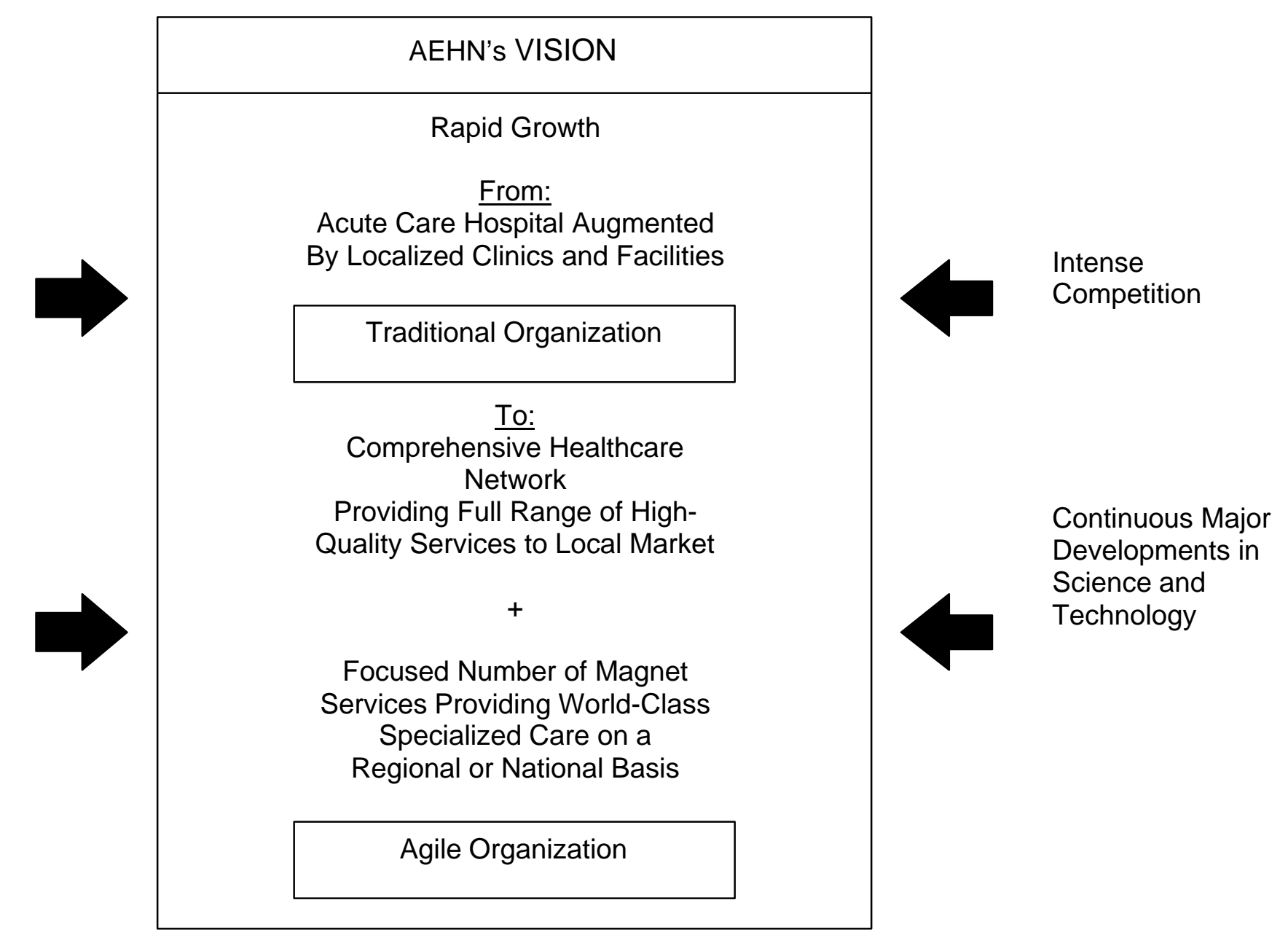




\title{
Strategizing for the Nineties
}

To pursue the CEO's vision and aspirations in the increasingly turbulent healthcare environment, $A E H N$ eventually crafted an emergent business strategy around three focal thrusts that, with the benefit of hindsight, we have labeled initiate, adapt, and deliver (see Figure 2).

\section{FIGURE 2 \\ AEHN's Three-Pronged Approach to Crafting Emergent Business Strategies}

\author{
Initiate \\ Continuous, timely addition of new \\ services through both external means \\ (e.g., mergers, acquisitions, and joint ventures) \\ and internal development \\ Adapt \\ Ongoing anticipation of opportunities \\ and threats and timely actions to \\ capitalize on the former and mitigate \\ the effects of the latter

\section{Deliver} \\ Offer consistently high quality services \\ while meeting or exceeding regulatory \\ and professional standards at \\ or below competitive costs
}

Initiate. Throughout the 1990s, AEHN increasingly assumed an amoeba-like quality as new lines of business were added even as old ones were revamped or, sometimes, dropped. Between 1990 and 1997, several new services were created from scratch. In addition, AEHN consummated more than a dozen strategic alliances of various types: risk-sharing ventures (e.g., a consortium with two other providers that contracted with managed care companies to provide a full range of healthcare services for their members -- a whole new business for $A E H N$ ), joint ventures (sometimes with smaller centers to extend AEHN's reach into such specialized services as alternative care and sometimes with less-specialized providers to give them access to AEHN's expertise in such magnet services such as rehabilitation and cardiac surgery and care), and even the acquisition of a nearby community hospital. Occasionally, overlapping and redundant services were closed or spun-off. These recurring initiatives resulted in a significant expansion in the breadth and depth of AEHN's reach and care, but not 
without a good deal of internal turmoil. Increasingly, employees came to view the term organizational design as a verb rather than a noun.

Adapt. Because of the anticipated environmental turbulence, AEHN strove to perfect an organizational capacity to sense and quickly respond to external challenges. By the mid-1990s, employees had become quite adept at anticipating and dealing with such things as intensifying stakeholder demands, recurring cost pressures, and the thrusts and parries of competitors. In a more or less typical case, a group of mid-level employees learned that competitors were easing ahead of $A E H N$ in the drive to acquire or align with local physicians' practices. Knowing that this was a potentially costly setback, these employees quickly formed a voluntary team to mobilize their peers to begin active recruiting of local doctors that they or their family members went to or otherwise knew. As a result, the tide turned and AEHN met its ambitious goal of 200 sign-ons well ahead of schedule. Repeated occurrences of this type meant that AEHN experienced fewer and fewer surprises and serious setbacks as time went on.

Deliver. Through the bobbing and weaving, AEHN remained focused on delivering the basics. During the mid-1990s, indices of patient satisfaction were at all-time highs. U.S. News and World Report repeatedly included AEHN on its list of the country's "100 Best" healthcare facilities. Industry associations, such as the Joint Commission on the Accreditation of Healthcare Organizations, provided consistently high ratings and praise for AEHN's unique culture and innovativeness. And these results were achieved under very tight cost constraints; key indicators, such as cost per patient discharged, ran as much as 30 percent below those of major competitors.

Results. This three-pronged approach to strategy produced some remarkable results. Between 1990 and 1997, AEHN grew very rapidly. Patient counts increased steadily and revenues more than doubled. At the same time, the total number of employees declined slightly, indicating a dramatic increase in productivity. Not surprisingly, then, in contrast to industry trends, AEHN operated in the black every year from 1991 on. (In 1997, just after the present study ended, AEHN became a founding member of the Jefferson Health System, a consortium of three complementary healthcare providers formed to enhance delivery capabilities and market strength in the face of continuing competition and ongoing inroads by managed care companies in the Philadelphia area.)

\section{Building Organizational Capability}

From the very beginning, AEHN's CEO realized that the organization's culture, characterized at the time as paternalistic, stable, and comfortably tolerable of unproductive behavior, was ill-suited to the challenges that lay ahead. But, beyond a few generalities -professional, challenging, and capable of nearly instantaneous change -- neither the CEO nor 
his Vice President of Human Resources was sure of what would be required. Accordingly, they set out to craft, through trial and error, an appropriately agile organization supported by a human resource strategy that would engender a workforce capable of simultaneously creating and learning to function in such a setting.

Our depictions of the process that was followed to derive this strategy and the content of the strategy are shown at the top and bottom, respectively, of Figure 3. The key behavioral outcomes (shown in the box to the far right of the content model) were derived directly from AEHN's three-pronged approach to business strategy: initiate, adapt, and deliver. These behaviors, the model suggests, were primarily fostered by the organization's ability to imbue employees with four essential agile attributes (labeled in the model dedicated, accountable, generative, and resilient). The inculcation of these agile attributes, in turn, was accomplished by relentlessly pursuing five interrelated human resource initiatives: forging common purpose, embedding core values, enriching work, promoting personal growth, and providing commensurate returns. And, finally, these five initiatives were enacted through a more or less integrated set of human resource programs and practices (some of which are shown in the boxes to the far left of the content model in Figure 3). This, then, is the broad framework of AEHN's agility-oriented human resource strategy; what follows is an elaboration of the model's main components and principal linkages. 
FIGURE 3

AEHN's Human Resource Strategy

Process Model

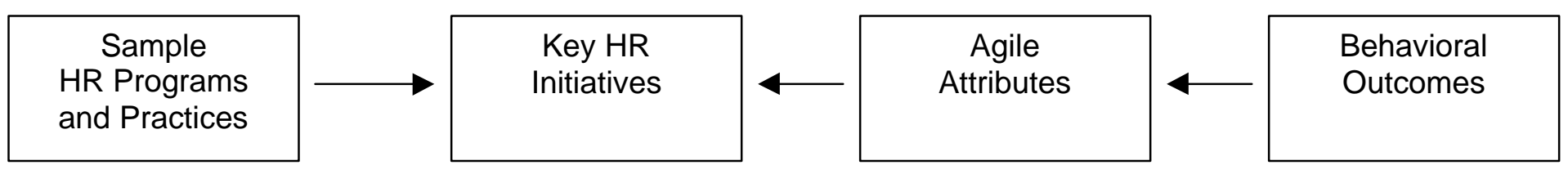

\section{Content Model}

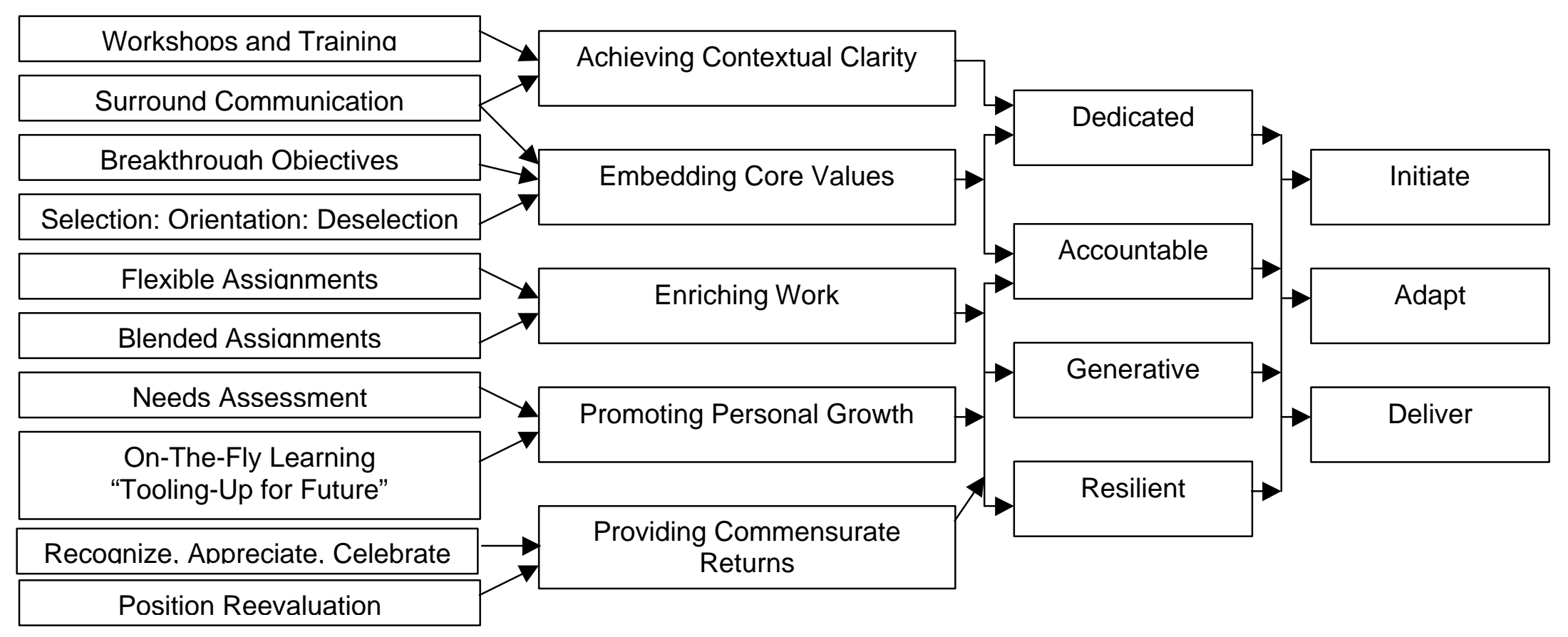




\section{AGILE BEHAVIORS AND ATTRIBUTES}

Clearly, AEHN's three-pronged approach to business strategy required a radical redefinition of requisite employee behaviors. The desired outcome, admittedly never fully realized, was to reach the point where every employee would readily and naturally do whatever he or she could to: (1) seek out and help pursue new business opportunities that would contribute to the realization of the organization's two-part vision (expand the network and develop magnet services); (2) anticipate potential opportunities and threats to the network's current and future operations and take action to capitalize on the former, while minimizing the probable effects of the latter; and (3) consistently provide world class, professionally certified services at very competitive costs, irrespective of what else might be happening in and around the organization..

But, how best to encourage and facilitate these behaviors? Through extensive experimentation, AEHN settled on the need to develop four agile attributes across all levels and types of employees:

Dedicated: By this was meant that every employee would be totally committed to AEHN's success. This had two facets. The first was to assure that everyone in the organization identified with $A E H N$ as a whole (i.e., as an integrated network) rather than with his or her particular sub-unit, specialty area, or function, as had often been the case in the past. The second facet involved a personal commitment based on a sense of perceived mutual advantage (personal success linked with organizational success, and vice versa). While AEHN's employees had always demonstrated a high level of commitment to the organization, this had primarily emanated from the tradition of paternalism and an implicit promise of job security. Thus, it tended to be manifest more through long-tenure than through (the additionally desired) behaviors of initiate, adapt, and deliver.

Accountable: The idea here was that all employees would hold themselves personally accountable for taking the actions necessary to pursue desired organizational results, as well as for achieving those results. This in contrast to the historical situation in which employees were used to waiting for guidance from supervisors before doing more than routine tasks and would sometimes play the blame game when favorable results failed to materialize.

Generative: This refers to the tendency for employees to proactively apply new knowledge and skills to search for new solutions. The 
challenge here was to break the comfortable mold of relying on existing competencies to continue doing familiar tasks in familiar ways.

Resilient: Meaning that employees embrace change, are comfortable with taking calculated risks, and bounce back quickly and easily when confronted with unanticipated events or results. This was basically a new notion since AEHN had traditionally been slow to change and had tended to shield most employees from the effects of even minor changes.

In sum, then, as we analyzed the data, it became clear that AEHN had decided to pursue organizational agility in large part by forming a workforce that could and would quickly and easily initiate, adapt, and deliver and that this, in turn, would require that each and every employee be: totally dedicated to the network's overall success, willing to hold him- or herself personally accountable for pursuing and achieving that success, personally and professionally proactive, and comfortable with change as an essential feature of organizational life. Given past practice, this was a tall order. To pursue it, AEHN relied heavily on five key human resource initiatives, to which attention is now turned.

\section{KEY HUMAN RESOURCE INITIATIVES AND ACTIONS}

Three of the five key human resource initiatives -- e.g., embedding core values, enriching work, and promoting personal growth -- were clearly articulated by AEHN; the remaining two -- achieving contextual clarity and providing commensurate returns -- were inferred from identified patterns in the objectives and content of the organization's human resource programs and practices. Each is discussed in turn in terms of its major goal(s), its explicit or implicit relationship to the four agile attributes (as shown in Figure 3), and its defining human resource program and practices (as indicated in Figure 3 and shown more fully in Figure 4). 
FIGURE 4

Human Resource Initiatives and Related Activities

for Organizational Agility

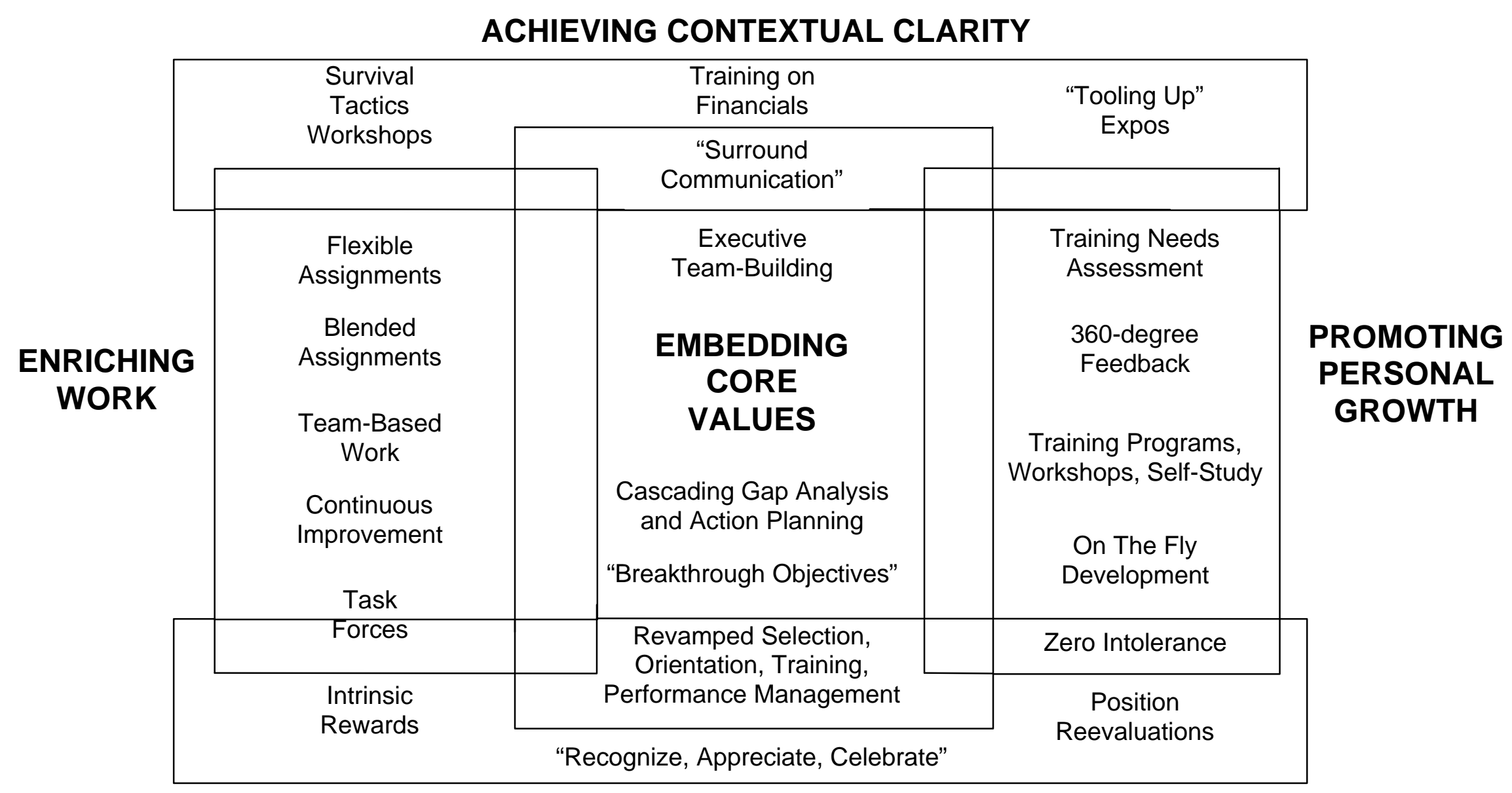

PROVIDING COMMENSURATE RETURNS 


\section{Achieving Contextual Clarity}

AEHN went to great lengths to assure that employees at all levels: (1) clearly understood the dynamic and threatening nature of the environment facing the healthcare industry, (2) fully grasped the gist and essentiality of the CEO's vision for the organization, (3) regularly tracked the organization's progress (or lack thereof), and (4) could see and articulate a link between their individual and collective actions and the performance of the total enterprise. It was apparently reasoned, as shown in Figure 3, that a firm grasp of environmental and organizational realities was essential if there was to be any hope of achieving a high level of employee dedication to the network's overall success.

Slowly but surely, AEHN assembled an impressive array of activities to achieve these educational objectives (see Figure 4). The techniques were fairly standard, but the messages were clearly new and delivered with an unusually high level of intensity. Using the rubric "Surround Communication", everything from bulletin boards, through employee newsletters and special forums, to focused training sessions were rejuvenated and revised. With respect to the external environment, AEHN explicitly opted for a full dose of unvarnished reality. Longneglected bulletin boards, for example, were routinely peppered with stories of local, regional, and national developments in the healthcare industry. New postings involving unexpected consolidations and closings of nearby facilities were especially effective at invoking ad hoc buzz sessions of the "wow, that could happen here" variety. Banners regularly appeared on bulletin boards with messages such as, "Are you ready for change? Are your skills ahead of the game?". Employee newsletters substituted social fare with substantive stories with a particular emphasis on the "so what for the individual employee". A representative article titled "Nursing Role Changes: Where Will You Fit In?" featured vignettes of nurses who had retooled and successfully moved on to meet new challenges and make enhanced contributions in critical areas.

Nary a piece of formal communication failed to mention, in one way or another, the twopart vision for AEHN and, when appropriate, why it was essential for the organization's longterm success. Frequent "Tooling-up Expos" brought employees together with representatives of management to share performance information and address questions of concern ("How do I know that the organization is succeeding?", "How do I get in on work redesign and crosstraining?"). Taking a page from "open-book management" (Stack, 1992), training opportunities were created for employees to learn how to read and interpret the wide range of performance and financial data regularly being made available. Workshops on "survival tactics in times of change" were made accessible to employees at all levels. 
Again, while the techniques are familiar enough, it was the message of contextual clarity that came through loud and clear: In a dynamic, rapidly changing environment where the premium is on organizational agility, the findings suggest, ignorance, far from being bliss, is a high-risk path.

\section{Embedding Core Values}

Early on, AEHN's CEO unilaterally established a set of core values for the organization (see Figure 5). The goal of the follow-on human resource initiative was to assure that all employees knew about, understood, shared, and lived these core values.

\section{FIGURE 5}

\section{AEHN's Core Values}

\section{WE ARE COMPASSIONATE}

We always present a welcoming, polished image

We show respect for cultural differences and the dignity of each individual We strive to put others at ease and to communicate in ways they can understand

We make hospitality and responsiveness to patients and each other a habit

\section{PROFESSIONALISM IS OUR HALLMARK}

We are totally dedicated to our patients and their families

We are enthusiastic, energetic, and hardworking

We demonstrate drive, spirit, and initiative in pursuit of our mission

We are confident in our tradition of success and leadership in our field

We are loyal to our organization and our values

\section{WE INSIST ON EVER-HIGHER QUALITY}

We take responsibility and make things work

We attend to the details

We recognize and celebrate excellent performance

We take pride in our work because we know that quality is not accidental

\section{WE RELY ON EACH OTHER}

We promote trust through honest transactions

We show respect for the work and ideas of others

We express our appreciation and thanks for each other's contributions

By giving our support and cooperation, we make each other stronger 
The CEO viewed the core values as central to his culture change initiative. Over time, others came to more explicitly reason that they could be used to facilitate the development of employee dedication and accountability (as shown in Figure 3). By being applied everywhere, the core values would encourage employees to identify with the organization as a whole. By imbuing work with a higher meaning, they would facilitate employees' emotional engagement with the organization. And by providing useful guidelines for making difficult decisions and serving as anchors of consistency in an otherwise swirling world, the core values would help employees feel more comfortable in taking responsibility and acting independently.

Accordingly, embedding and sustaining the core values became the central human resource initiative in AEHN's drive to agility. In the early going, the core values served as the centerpiece of a team-building effort designed to convert AEHN's 14 top executives from a group of individuals who sometimes worked together into a fully functional team. For almost a year, the executives spent time clarifying and debating the core values (minor changes were made in the CEO's original version), developing an understanding of how living the core values would contribute to the pursuit of AEHN's vision and the enhancement of organizational agility, doing gap analyses to assess the extent to which the executives were living the core values as individuals and as a team, closing existing gaps through individual and team actions, and creating a process for cascading the core values down through the organization (see Figure 4).

In the cascading process, "Surround Communication" was once again a focal feature. At every opportunity, references to the core values were weaved into various forms of employee communication. Special video tapes, audio tapes, scripts, print pieces, and e-mail messages were created and made available for supervisors and managers to use in preparing and conducting employee meetings and training sessions. Managers, supervisors and trainers were coached on the content, meaning, and application of the core values. Organization-wide "Breakthrough Objectives" were established around selected core values. One such objective, for example, titled "First Impressions Last", was created to insure that the first few seconds of every interaction with patients, family members, and the like reflected the core value of compassion (presenting a welcoming, polished image; respecting cultural differences and the dignity of each individual; striving to put others at ease; and so forth). This, like all "Breakthrough Objectives", was widely communicated with great fanfare. Supervisors and team leaders were encouraged to use games and contests to facilitate implementation. By way of assistance, help clinics, guidebooks, support services, and even mentors were made available. Informal measures (e.g., small, random surveys of patients and family members) were used to track progress. 
Simultaneously, following the lead of the top management team, each level of the organization performed gap analyses to uncover situations in which everyday individual and team behavior in various units failed to live up to the core values and, where necessary, conducted action planning and follow-up activities to close the gaps. This process involved all levels of the organization including administrative and physician leaders $(n=90)$, middle managers ( $n=150)$, supervisors ( $n=300)$, and eventually front-line staff and volunteers. In one activity, teams set a goal of removing one "dead moose" from the organization. A "dead moose" was defined as something that was widely known, clearly inconsistent with the core values and pursuit of organizational effectiveness, and generally ignored. Strong messages reverberated throughout the organization as these "undiscussables" began to fall, and perhaps no more so than in a couple of instances when highly placed leaders were identified as "dead moose" and, following unsuccessful attempts to help them change their behaviors, were terminated.

Interdisciplinary teams ("Think Tanks") were formed to examine the extent to which AEHN's human resource policies, programs, and practices were consistent with and reinforced the core values. Over time, extensive changes were made in several areas:

Selection: Under the rubric "Hiring the Best", the selection process was revised to add an assessment of applicants' core values by means of situational interviewing. Values discrepancies, as much as competency deficiencies, were grounds for rejection. Interviewers were primed with set questions and interviewing tips, and were also trained on interviewing techniques. (Several new hires indicated that they had been influenced in their decisions to join $A E H N$ in part by the clear values communicated during the selection process.)

$>\quad$ New Employee Orientation: A half-day session was added to the standard new employee orientation process to explain and demonstrate the meaning of the core values and to stress the importance of living them day-to-day.

Training: Considerable values-related training occurred, as noted above. In addition, the content, as well as the announcements, of some technical training programs, as well as virtually all non-technical training programs, were revamped to show how the subject matter linked to one or more of the core values.

Performance Management: This system was totally revamped to focus heavily on behavioral manifestations of the core values, as well as demonstrations of technical and managerial competencies and desired results. A voluntary 360-degree feedback process was instituted to assist supervisors and managers in assessing behavior-values gaps and to provide developmental tools and coaching where needed. 
Promotions: Over time, as the core values became embedded, promotion procedures were revamped to reflect the same criteria and rigor that were applied to new hires. As a result, living the core values became a de facto hurdle for individuals being considered for promotion to or through supervisory or managerial positions.

Rewards and Recognition: This area was intensively studied, but for reasons noted below, only relatively marginal changes were made (beyond the effects of the previously noted changes in the performance management and promotion processes).

Eventually, the core values became used as one means, first, of attracting potential alliance partners and, second, of assessing the degree of cultural fit between AEHN and these organizations (more on this later).

No survey was ever taken. But, managerial estimates suggested that, as a result of these many activities, about 70 and 50 percent of AEHN's exempt and non-exempt employees, respectively, truly understood, shared, and consciously lived the core values day-to-day on the job. (The outside researchers generated higher estimates based on informal discussions with employees at various locations; even in such areas as the cafeteria there were very few employees who, when asked, could not both verbalize the core values and give specific examples of how they played out in their work.)

\section{Enriching Work}

The goal here: To have employees at all organizational levels performing work in a manner that reflected three general principles: (1) aligned with the broad behavioral outcomes of initiate, adapt, and deliver, (2) consistent with the core values, and (3) expanded to develop and utilize multiple competencies.

Constant experimentation with work design along these lines contributed to the development of three of the four agile attributes (refer again to Figure 3). First, it enhanced accountability by encouraging employees to view themselves more as owners of fluid assignments responsible for achieving results than as occupants of fixed positions responsible for performing assigned duties; the true measure of success became contribution to the organization rather than simply fulfilling job responsibilities. Second, it induced employees to be more generative since the process made it obvious that current knowledge and skills would very likely be inadequate as work continually evolved. And finally, the reality of constant 
experimentation served to reinforce the norm of continuous change and the need for greater employee resilience.

At the time of this study, some 15 to 20 percent of the employees at AEHN were involved in work redesign experiments. (It was estimated that as many as 70 percent had been so involved at one point or another during the transformation.) These experiments generally took one of three forms (as shown in Figure 4):

Flexible Assignments: Here employees continued to use the same or a similar set of technical competencies, but applied them in different locations throughout the network (e.g., during the course of a day or week physical therapists might work in two, three, or even four distinct units with a wide variety of patients). The primary driver behind flexible assignments was the need to meet fluctuating staffing requirements while keeping headcount under control. But, the practice also helped to broaden perspectives, enhance social networks, promote organizational learning, and (as noted above) encourage employee flexibility.

Blended Assignments: Past practice had created many situations at $A E H N$ in which routine services (e.g., taking vital signs, drawing blood, and administering tests) were each performed by different specialists. Several experiments were conducted in which various combinations of such tasks were compressed into one assignment, called Patient Care Associate. Following the necessary training, then, each PCA would take responsibility for delivering the full range of relevant services to a smaller, defined set of patients. This not only facilitated the delivery of care in a manner more consistent with AEHN's core values (e.g., on a more personal basis), but also created more autonomous, challenging, and interesting work for the employees involved.

Team-based Work: The idea here was to look for opportunities to create teams of care givers to provide a full range of routine services focused on the patients in a particular unit. These teams were essentially self-managed and, thus, had had the flexibility to assign and carry out tasks on their own volition to provide "seamless, patient-focused care". Experimentation along these lines was limited, primarily to certain magnet services (e.g., cardiac care). But, where fully implemented, team-based work resulted in improved care, enhanced patient satisfaction, and lower costs (since it took fewer people to provide the essential 
services). And, of course, the employees involved were simultaneously encouraged to become increasingly accountable, generative, and resilient.

Virtually all of AEHN's experiments in enriching work were initiated and carried out by employees (outside consultants were rarely used). In time, then, the process became institutionalized. Employees in positions that had not been radically reworked were encouraged to be on the lookout for opportunities to make improvements consistent with the three principles noted above; that is, they were urged to continuously work the process even as they were processing the work. And, whenever a position (not currently or recently involved in work redesign) became vacant, a team was used to determine if the position could and should be revamped to bring it more closely into compliance with the three basic principles of work redesign.

Beyond these efforts, AEHN also strived to involve as many employees as possible in other off-line, more or less temporary teams. At any given time, several task forces were in place analyzing, designing, or implementing new policies, programs, procedures, and practices. Again, in addition to accomplishing essential work, this activity served to foster important agile attributes (accountable, generative, and resilient) and also helped to allay anxieties about the new, more agile way of operating.

\section{Promoting Personal Growth}

Through this initiative AEHN hoped to reach the point where all employees were taking personal responsibility for their own development, not only to enhance performance in current assignments, but also to prepare for whatever the future might bring. The message (delivered through the various components of "Surround Communication" noted above) reinforced the agility challenge: In a constantly changing world, standing still is tantamount to becoming obsolete and, thus, expendable; those who hope to succeed with $A E H N$, therefore, have no real alternative but to do everything possible to stay well ahead on the learning curve. Thus, as shown in Figure 3, while this initiative was intended to foster the generative and resilience attributes, it was specifically framed in a way that clearly emphasized individual accountability.

Still, AEHN was committed to helping employees succeed in their development efforts and took several steps to help them do so (as shown in Figure 4). Development needs for current assignments were identified through the aforementioned performance management system and 360-degree feedback process, as well as a separate process for tracking proficiency in technical competencies (to make sure these weren't diminished as a result of performing enriched work). Development needs for future assignments were less easily 
identified, although efforts were made to keep employees abreast of anticipated experiments with work redesign, emerging treatments and technologies, likely new lines of business, and so on. A career planning process was also developed to provide templates, tools, and resources (including coaches) to help employees clarify career aspirations, identify competency gaps, and develop development plans. The inevitable caveat: Given the dynamics of healthcare in general and $A E H N$ in particular, there is a distinct possibility that the competency requirements of aspired-to positions may well change, even if the positions themselves should happen to survive. So, employees were strongly encouraged to stay attuned.

AEHN invested heavily in training. There were a fair number of standard classroom programs, especially to meet recurring needs, both technical and otherwise. Real-time workshops and brown bag sessions became standard fare to help employees keep abreast of rapidly emerging developments. Self-study programs were purchased or developed as resources permitted. But, because of the premium placed on the need to learn and apply new knowledge quickly, much of the requisite training was done the agile way -- on the job, on the fly (always, of course, with a keen eye on maintaining quality). Finally, the various development activities were supplemented by a job posting system that served as much to encourage employees to take initiative in reaching out for development opportunities as it did to fill vacant positions.

As suggested, the success of the personal growth initiative rested on a policy of zero tolerance of employees who failed to pursue and eventually succeed at needed development. Truth be told, it was only after a few highly visible terminations had occurred that the implications of this initiative became thoroughly internalized.

\section{Providing Commensurate Returns}

AEHN sought to provide all employees with monetary and non-monetary returns that were perceived as generally equal to their increasing contributions to the organization. There was, of course, a genuine desire to do everything possible to see that employees were treated fairly. In addition, there was a concern that non-commensurate returns (and perceptions of inequity) would undermine the positive effects of the other key human resource initiatives (as suggested in Figure 3), primarily by making it more difficult to attract and retain employees with requisite technical competencies and agile attributes.

On balance, AEHN put less emphasis on monetary than on non-monetary returns. This seemed to be dictated in equal measure by cost constraints, a tendency to downplay the role of pay as a motivator of healthcare professionals, and real uncertainty about how to design a pay system that would promote organizational agility. 
On the non-monetary side, enriched assignments and enhanced opportunities for development were thought to provide many, and especially the most coveted, employees with valued intrinsic rewards (such as a sense of challenge, achievement, and growth). Beyond these things, AEHN put a great deal of emphasis on "Recognize, Appreciate, Celebrate", an umbrella concept encompassing an array of activities designed around the core value of "reliance on each other" (show respect for the work and ideas of others, express our appreciation and thanks for each other's contributions, giving support and cooperation to make each other stronger). The idea was to catch people doing things right and shower them with positive feedback and awards in highly visible ways. A toolkit and accompanying workshop were developed to both encourage and make it easy for supervisors, peers, and even patients to acknowledge and laud positive contributions to the cause. Some activities were unit or team based; these included, for example, public postings of such things as letters from satisfied patients and the written results of quality service audits and certification reviews. Other activities were more individual in nature; examples included "pat on the back notices" and a "celebration of a risk taken award" (given for a good effort irrespective of result). Supervisors were constantly reminded of the need to allocate adequate time in meetings and elsewhere to making sure that desired employee behaviors were consistently reinforced and were routinely evaluated on how well this responsibility was carried out.

In contrast, for the reasons noted above, AEHN treated pay as a lag variable in the transformation to agility. Only relatively minor changes were made to the basic pay plan that had been in place for many years (a job-based system with pay levels pegged to the mid-point of the market and pay increases determined by a combination of ability to pay, cost-of-living adjustments, and merit). Broad-banding was introduced to simplify the system and introduce an element of flexibility. The previously noted changes in the performance management system brought the organization's core values into play in determining individual pay increases. And, from time to time, a few positions were reevaluated to reflect sustained changes in work redesign and the pay levels of a few high performing individuals with rare technical skills were significantly adjusted by pegging their rates to the $75^{\text {th }}$ rather than $50^{\text {th }}$ percentile of the market.

As this study was drawing to a close, there was (again) concern that these piecemeal adjustments were not fully meeting the goal of providing commensurate returns (and fostering, or at least not interfering with, the development of the various agile attributes). Specifically, it was felt that not enough was being done to: reward employees for organization-wide results (given the desire for dedication to the network as a whole); systematically recognize the increased responsibility associated with enriched work; and reward team performance in those 
instances where team-based work had taken hold. So, in keeping with the prevailing philosophy, a task force had been formed to examine these issues.

\section{Summary}

The five key human resource initiatives were pivotal to AEHN's pursuit of organizational agility for two main reasons. First, every effort was made to assure that they were businessbased. The logic worked as previously noted -- from AEHN's three-pronged business strategy back through three behavioral outcomes (initiate where possible, adapt when necessary, and deliver always) and a manageable number of desired agile attributes to a similarly manageable number of human resource initiatives. Second, once firmly established, the human resource initiatives helped the organization to stay focused. Human resource programs and practices that promoted the initiatives (and thus organizational agility) were actively undertaken, while those that did not were not (unless they were legally or otherwise mandated). Further, as the experience with the pay system shows, the initiatives (as well as the attributes and behaviors) provided a means of assessing progress from time to time and deciding when and how to set priorities for making necessary refinements and adjustments.

\section{LESSONS LEARNED}

The need to compete in increasingly dynamic environments requires new paradigms to replace the mature models that dominate much of today's thinking about business strategies and organizations. New paradigms of business strategies and organizations -- such as marketplace and organizational agility (by whatever names) -- in turn require new ways of thinking about human resource strategy (Dyer \& Shafer, 1999). Accordingly, we set out to study the experiences, and in particular the people-related experiences, of an organization that was (in retrospect) deliberately trying to "compete on the edge" (Brown \& Eisenhardt, 1998) by effectuating a new operating model. Notwithstanding some limitations of the study (noted below), we believe that it holds a number of lessons that are potentially important for researchers and practitioners who are, or will be, studying or trying to create and sustain agile organizations in the years ahead.

Lesson 1: Even in the most dynamic environment, not everything can be emergent.

Given the uncertainties of the healthcare industry, AEHN's CEO realized the futility of detailed strategic planning. But, he was also unwilling to rely on unbridled emergence. Rather, he sought a middle ground (endorsed by more recent researchers such as Brown \& Eisenhardt, 1998) by staking out a vision and a set of core values to provide "skyhooks" of stability for employees to hang onto as emergent business and organizational strategies were formed and 
the culture change progressed. He envisioned a bigger, better AEHN encompassing both a comprehensive healthcare network providing unmatched "cradle to grave" care for neighborhood clientele and a focused set of magnet services providing world-class specialized care to regional or even national clientele. Further, he dictated (not too strong a term) that, come what may, the new AEHN would operate in accordance with the values of compassion, professionalism, ever-increasing quality, and mutual reliance. The vision not only gave form to the activities -- initiate, adapt, deliver -- that shaped the organization's emergent business strategies, but also gave focus to the supporting human resource strategy. And for a long time, the initiative designed to embed the core values constituted the centerpiece of this human resource strategy.

Lesson 2: Organizational agility doesn't just happen; it has to be deliberately pursued Early on, AEHN clearly had no master plan for achieving organizational agility. But, the CEO and the Vice President of Human Resources did have a vague concept of a "nimble, change-hardy" culture that, over time, provided an increasingly clear template against which to assess the appropriateness of proposed changes to the organization and, especially, its human resource activities. Today, those embarking on a journey to organizational agility have a somewhat clearer path to follow thanks to the pioneering efforts of organizations such as AEHN and a rapidly accumulating body of relevant theory and research, much of it tied to chaos or complexity theory (Dyer \& Shafer, 1999; Maguire \& McKelvey, 1999).

Lesson 3: Guiding models facilitate the formation of an agility-oriented human resource strategy

Somewhere along the way, AEHN developed a partially explicit process model for forming an agility-oriented human resource strategy (as shown at the top of Figure 3). It incorporated the notion now known as vertical fit (Wright \& McMahan, 1992) by clarifying a line of sight (i.e., a tentative path model) from the activities that shaped the organization's emergent business strategies back through a set of agile attributes to a set of key human resource initiatives which, in turn, were used to choose and design various human resource programs and practices. Over time, as a result of experimenting with the process model, AEHN (again, partly explicitly and partly implicitly) derived a corresponding content model by specifying desired behavioral outcomes and clarifying the desired agile attributes, requisite human resource initiatives, and specific human resource programs and practices (as shown at the bottom of Figure 3 and in Figure 4). AEHN's particular models may or may not hold up over 
time or across aspiring agile organizations. But, its experiences do strongly suggest that tight vertical fit is both possible and desirable when devising agility-oriented human resource strategies. Further, the pursuit of such fit can be very helpful to human resource strategists. Devising and revising process and content models helps to clarify thinking, focus effort, speed implementation, enhance organizational learning, and above all foster business relevance.

Lesson 4: A limited number of integrated or synergistic human resource initiatives define an agility-oriented human resource strategy

AEHN, as noted, settled on five key human resource initiatives. This proved to be a manageable and apparently sufficient number to effectuate an effective agility-oriented human resource strategy primarily, we believe, because those making the key decisions consciously searched for synergies, or horizontal fit (Wright \& McMahan, 1992), to form an integrated, nonoverlapping set. To oversimplify only slightly, achieving contextual clarity and embedding core values served to focus employee attention on the CEO's vision and on the ways in which they could add value through their own activities, and they provided an element of stability in an otherwise rapidly moving world (as noted above). Enriching work and promoting personal growth, in turn, fostered initiative and provided both the rationale and space required for employees to be flexible and proactive. Providing commensurate returns (especially, as noted, the non-monetary component) served to reinforce employees who, initially, exemplified the organization's core values and, later, made important contributions to emergent strategies, willingly gravitated toward enriched work, eagerly pursued personal growth opportunities, and effectively delivered high quality, cost effective services.

Our findings suggest that for clarity and parsimony agility-oriented (and probably other) human resource strategies should be framed, and studied, around a limited number of initiatives (or principles) rather than around an inevitably larger number of programs and practices (Becker \& Gerhart, 1996). They also reinforce the long-extolled virtues of vertical fit and provide potentially helpful guidelines for pursuing such fit. And, finally, the findings suggest, contrary to some views (e.g., Wright \& Snell, 1998) that both flexibility (here initiating and adapting) and efficiency (here delivering) can be attained through agility-oriented human resource strategies characterized by a high degree of horizontal fit (or synergy).

Lesson 5: Key human resource initiatives guide the choice of human resource programs and practices

Over time, AEHN used the key human resource initiatives to guide the choice of human resource programs and practices (except those that were legally or otherwise mandated). This worked in two ways. First, initiatives were continually examined for shortcomings and, where 
necessary, existing programs and practices were improved or new ones were tried (if feasible and desirable alternatives could be devised, which was not always the case -- as indicated by the situation with the pay system). Second, proposed new programs or practices were analyzed for probable effects on the initiatives and implemented only if they appeared to be relatively low cost ways to pursue one or more of them. This put a premium on programs and practices that addressed more than one initiative (such as "Surround Communication"). Focusing on a limited number of key human resource initiatives, rather than programs and practices not only helps to rationalize the choice of human resource programs and practices, but also provides a way for human resource professionals to lessen their increasingly infamous addiction to fads, folderol, and putative best practices.

These lessons, of course, were derived by a team of researchers replete with a particular set of individual and collective lenses and perspectives. They are based on data from a single case study of an imperfect organization that appeared to do many things, but obviously not everything, right. And it was an organization that operated in a unique industry during a particular period of time. So, it remains to be seen to what extent, if at all, the lessons derived from this experience hold up across methodologies, organizations, industries, and time. At this juncture, then, we simply hope that they will prove helpful to researchers in planning future studies and to those out there in the rapidly changing world who by design or chance find themselves in active pursuit of organizational agility. 


\section{REFERENCES}

Becker, B. \& Gerhart, B. (1996). The impact of human resource management on organizational performance: Progress and prospects. Academy of Management Journal, 39, 779-801.

Boudreau, J. \& Ramstad, P. (1999). Human resource metrics: Can measures be strategic? In P. Wright, L. Dyer, J. Boudreau \& G. Milkovich (eds). Strategic human resource management in the $21^{\text {st }}$ century. Research in personnel and human resource management, supplement 4. Stamford, CT: JAI Press.

Brown, S. \& Eisenhardt, K. (1998). Competing on the edge: Strategy as structured chaos. Boston: Harvard Business School Press.

Dyer, L. \& Shafer, R. (1999). From human resource strategy to organizational effectiveness: Lessons from research on organizational agility. In P. Wright, L. Dyer, J. Boudreau \& G. Milkovich (eds). Strategic human resource management in the $21^{\text {st }}$ century. Research in personnel and human resource management, supplement 4. Stamford, CT: JAI Press.

Eisenhardt, K. (1995). Building theories from case study research. In G. Huber \& A. Van de Ven (eds). Longitudinal field research methods. Thousand Oaks, CA: Sage.

Fradette, M. \& Michaud, S. (1998). The power of corporate kinetics. New York: Simon \& Schuster.

Glaser, B. \& A. Strauss (1967). The discovery of grounded theory: Strategies for qualitative research. Chicago: Aldine.

Goldman, S., Nagel, R. \& Preiss, K. (1995). Agile Competitors and Virtual Organizations: Strategies for enriching the customer. New York: Van Nostrand Reinhold.

Gunneson, A. (1997). Transitioning to agility: Creating the $21^{\text {st }}$ century enterprise. Reading, MA: Addison-Wesley.

Maguire, S. \& McKelvey, B. (1999). Complexity and management: Where are we? Emergence, 1 , entire special issue.

Mintzberg, H. (1989). Mintzberg on management. New York: The Free Press.

Shafer, R. (1997). Creating organizational agility: The human resource dimension. Unpublished Ph.D. dissertation, Cornell University.

Ulrich, D. (1997). Human resource champions. Boston: Harvard Business School Press.

Wright, P. \& McMahan, G. (1992). Theoretical perspectives for strategic human resource management. Journal of Management, 18, 295-320.

Wright, P. \& Snell. S. (1998). Toward a unifying framework for exploring fit and flexibility in strategic human resource management. Academy of Management Review, 23, 756772. 
Yin, R. (1994). Case study research: Design and methods. London: Sage.

Youngblood, M. (1997). Life at the edge of chaos: Creating the quantum organization. Dallas: Perceval Publishing. 